\title{
Ideas y políticas migratorias españolas a fines del Antiguo Régimen: el caso astur-galaico'
}

\author{
Nadia Andrea De Cristóforis \\ Universidad de Buenos Aires
}

En las postrimerías del setecientos las salidas de gallegos y asturianos hacia América o hacia distintos puntos de la Península Ibérica se incrementaron. En el contexto del predominio de una mentalidad poblacionista, dichos desplazamientos fueron percibidos en general de manera negativa, aunque no faltaron voces que, contrariamente, enfatizaron sus efectos positivos. En consonancia con estas diferentes ideas, las políticas migratorias de la corona española pusieron de manifiesto una cierta ambigüedad: si por un lado tendieron a restringir y controlar las emigraciones, por otro lado, también las terminaron alentando. En esta última dirección, tanto las expediciones de colonos como el ejército fueron empleados como vías de poblamiento.

PALABRAS CLAVE: políticas migratorias, ideas migratorias, monarquía española, gallegos, asturianos, campañas pobladoras, ejército.

By the end of the 18th century, the departures of Galicians and Asturians to America or different points of the Iberian Peninsula increased. In the context of the predominance of a poblacionista mentality, such movements were generally perceived in a negative way. However, there were voices that emphasized their positive effects. According with these different ideas, the Spanish Crown's migration policies showed a certain ambiguity: on one hand, they tended to restrict and control the emigrations, and on the other, they finished encouraging them. In this last direction, the colonists' expeditions as well as the army were employed as ways of settlement.

KEYWORDS: migration policies, points of view about migrations, Spanish monarchy, Galicians, Asturians, settlement campaigns, army.

A fines de la etapa moderna una parte de la población de Galicia y Asturias participó de diferentes procesos de movilidad espacial. Algunos de estos migrantes siguieron los itinerarios tradicionales hacia distintos

1 Este trabajo fue realizado gracias a una beca otorgada por el Consejo Nacional de Investigaciones Científicas y Técnicas (Argentina) y a un subsidio del Centro de Estudios Hispánicos e Iberoamericanos (Fundación Carolina, España), destinado a financiar el proyecto de investigación CEHI 08/03, dirigido por el Dr. Fernando Devoto. Una versión preliminar del presente artículo fue presentada como ponencia en las "Cuartas Jornadas Internacionales de España", organizadas por la Fundación para la Historia de España, el 9 y 10 de septiembre de 2004. Agradezco a Carlos Zubillaga y a Rosario Márquez Macías los comentarios realizados en dicha oportunidad, a propósito de la misma. 
ámbitos de la Península Ibérica (Castilla, Andalucía, Portugal, por ejemplo), mientras que otros se aventuraron hacia tierras más lejanas, como las americanas (en especial, hacia el área mexicana, antillana o rioplatense). ${ }^{2}$ De carácter temporal o definitivo, estos traslados llamaron la atención de la monarquía hispánica y de muchos pensadores de la época, ligados a ella de diversos modos. En general, prevaleció la idea de que las migraciones de peninsulares producían efectos negativos, opuestos a los intereses de la nación. El peso de la mentalidad poblacionista, que asociaba el crecimiento de la población con la felicidad del Estado, condujo a generar una interesante reflexión sobre estos desplazamientos humanos, sus causas y con-

2 La bibliografía sobre estos movimientos migratorios es muy amplia. Para los desplazamientos intrapeninsulares se pueden consultar, entre muchos otros: Meijide Pardo, Antonio: La emigración gallega intrapeninsular en el siglo XVIII, Monografías Histórico-Sociales, Vol. VI, Consejo Superior de Investigaciones Científicas, Madrid, 1960; Ansón Calvo, María Carmen: "Movimientos migratorios en Asturias desde 1768 a 1857", en Actas de la Primera Conferencia Europea de la Comisión Internacional de Demografía Histórica, Xunta de Galicia, Consellería de Educación e Ordenación Universitaria, 1993, págs. 457-474; Dubert, Isidro: Del campo a la ciudad. Migraciones, familia y espacio urbano en la historia de Galicia, 1708-1924, Nigra Imaxe-Consorcio de Santiago, Vigo, 2001; González Lopo, Domingo Luis: "La emigración a Portugal desde el suroeste de Galicia en los siglos XVIII al XX", en AAVV, Emigração / Imigração em Portugal, Actas do "Coloquio Internacional sobre Emigração e Imigração em Portugal (séc. XIX-XX)”, Editorial Fragmentos, Lisboa, 1993, págs. 373391. Sobre las migraciones ultramarinas de asturianos y gallegos con dirección a América, a fines del setecientos, véase por ejemplo: Rodríguez, Jesús Jerónimo: Asturias y América, (Colección "Las Españas y América”), Editorial Mapfre, Madrid, 1992; Díaz-Jove, Santiago: Gijoneses en Indias. Notas sobre emigración e índice geobiográfico (1700-1825), Editorial Auseva, Gijón, 1992; Fernández Romero, Ana María: La huella de los indianos en la documentación notarial, Consejo de Comunidades Asturianas, Oviedo, 1989; Barreiro Mallón, Baudilio: "Ritmo, causas y consecuencias de la emigración asturiana a América, 1700-1900”, en AAVV, Emigración española y portuguesa a América, Actas del II Congreso de la Asociación de Demografía Histórica, Vol. 1, Ediciones de Historia, Bilbao, 1990, págs. 73-88; Anes Álvarez, Rafael: La emigración de asturianos a América, (Colección "Cruzar el Charco"), Fundación Archivo de Indianos, Colombres, 1993; Villares, Ramón y Fernández, Marcelino: Historia da emigración galega a América, Xunta de Galicia, Tórculo Artes Gráficas, 1996; Vázquez González, Alejandro: La emigración gallega a América, 1830-1930, Memoria de doctorado inédita, Facultade de Ciencias Económicas e Empresariais, Universidade de Santiago de Compostela, Santiago de Compostela, 1999, 2 Vols; Rodríguez Galdo, María Xosé: O fluxo migratorio dos séculos XVIII ó XX, Xunta de Galicia, Interprint, 1995; Márquez Macías, Rosario: "La emigración gallega a América en la época del comercio libre (1765-1824)", en Revista da Comisión Galega do Quinto Centenario, N. ${ }^{\circ}$ 4, Santiago de Compostela, 1989, págs. 37-56; Eiras Roel, Antonio y Rey Castelao, Ofelia: Los gallegos y América, (Colección "Las Españas y América"), Ed. Mapfre, Madrid, 1992; Rey Castelao, Ofelia: "Los gallegos en el Río de la Plata durante la época colonial”, en Núñez Seixas, Xosé (ed.): La Galicia Austral. La inmigración gallega en la Argentina, (Colección "La Argentina Plural"), Ed. Biblos, Buenos Aires, 2001, págs. 23-51. Una clasificación de los tipos de migraciones en la España del Antiguo Régimen puede consultarse en Eiras Roel, Antonio: "Migraciones internas y medium-distance en España en la edad moderna”, en Eiras Roel, Antonio y Rey Castelao, Ofelia (eds.): Migraciones internas y medium-distance en la Península Ibérica, 1500-1900, Vol. II, Xunta de Galicia, Santiago de Compostela, 1994, págs. 37-83. 
secuencias para la estructura productiva del país. ${ }^{3}$ Este trabajo retomará estas ideas sobre la emigración, al tiempo que intentará focalizar algunas políticas concretas vinculadas a ellas. Comenzaremos aludiendo a determinadas investigaciones que aportaron elementos de análisis para sostener la idea de un incremento de la emigración de gallegos y asturianos hacia el exterior, en las postrimerías de la etapa moderna. Luego analizaremos las visiones de los contemporáneos sobre estos desplazamientos de fines del Antiguo Régimen. En especial, haremos hincapié en las distintas explicaciones elaboradas a propósito de la movilidad espacial intrapeninsular y oceánica de la época. ${ }^{4}$ En la tercera parte examinaremos de qué modo la prevaleciente percepción pesimista de los movimientos de personas convivió con otra más positiva, tendiente a justificar el traslado planificado de españoles, con dirección al Continente Americano. En este sentido, discutiremos el rol que cumplieron las expediciones de colonos y el ejército como vías de poblamiento. Por ello, en la cuarta parte nos detendremos en el estudio de una campaña oficial particular: la organizada hacia el Río de la Plata, con emigrantes gallegos, asturianos y castellano-leoneses.

\section{Los flujos astur-galaicos a fines del Antiguo Régimen}

A lo largo del siglo XVIII las migraciones desde Galicia y Asturias hacia el exterior aumentaron progresivamente. Existen ciertos obstáculos para conocer las dimensiones exactas que alcanzaron estas corrientes, en especial, porque la documentación disponible no logra dar cuenta de manera cabal del volumen total de la emigración. Las licencias y pasaportes que se han conservado en el Archivo General de Indias, por ejemplo, hacen referencia únicamente a las salidas legales que se llevaron a cabo por los puertos de Sevilla o Cádiz, dejando de lado aquellas que se produjeron de forma ilegal, o las que tuvieron lugar por puertos diferentes a los

3 Sobre la evolución de la actitud poblacionista en España, véase Rodríguez, Manuel Martín: Pensamiento económico español sobre la población, Ed. Pirámide, Madrid, 1984. Ver también Nadal, Jordi: La población española (Siglos XVI a XX), Ariel, Barcelona, 1984, págs. 121-127.

4 Existe una obra que ha abordado los móviles de la emigración española en la etapa masiva, deteniéndose en las percepciones que los escritores, políticos y legisladores contemporáneos tuvieron de la misma. Véase Sánchez Alonso, Blanca: Las causas de la emigración española, 1880-1930, Ed. Alianza, Madrid, 1995, págs. 62-93. Una versión de esta última cuestión puede encontrarse en Sánchez Alonso, Blanca: "La visión contemporánea de la emigración española", en Estudios Migratorios Latinoamericanos, Año 4, N. ${ }^{\circ}$ 13, Buenos Aires, 1989, págs. 439-466. 
del sur peninsular. ${ }^{5}$ La explotación de los padrones de población y de otras fuentes notariales, parroquiales o judiciales favoreció una aproximación indirecta a los ritmos de las salidas desde determinadas áreas del noroeste hispánico. Pero los resultados obtenidos en este sentido son algo provisorios y fragmentarios por el momento, y ameritan ser profundizados en futuras indagaciones. ${ }^{6}$

Sin embargo, y aún con las limitaciones señaladas, los trabajos mencionados anteriormente permiten abonar interesantes elementos de análisis a la hipótesis de un aumento progresivo de la tasa emigratoria dentro de Galicia y Asturias, desde mediados del siglo XVIII. A un nivel geográfico, este crecimiento de los flujos no afectó a ambas regiones de manera homogénea. Las emigraciones hacia América, por ejemplo, se originaron predominantemente en las áreas costeras del litoral atlántico y cantábrico. ${ }^{7}$ Allí había más probabilidades de disponer de la información necesaria para partir a ultramar, ya sea por la acción de los capitanes o marineros que difundían noticias del Nuevo Continente en las zonas próximas a los puertos, o por la propaganda llevada a cabo por los retornados, quienes a menudo brindaban imágenes prometedoras sobre los desplazamientos transoceánicos. En cambio, las migraciones hacia distintos puntos de la Península, que presentaron un carácter estacional, tendiente a complementar los limitados ingresos de las economías campesinas, podían proceder de ámbitos diferentes a los que caracterizaban a las migraciones ultramarinas. Para ejemplificar, podríamos señalar que los desplazamientos de corta o mediana dis-

5 Algunos estudios que han explotado las mencionadas fuentes, en relación con el setecientos, y con interesantes resultados, son los siguientes: Macías Domínguez, Isabelo: La llamada del nuevo mundo. La emigración española a América (1701-1750), Universidad de Sevilla, 1999; Márquez Macías, Rosario: La emigración española a América (1765-1824), Oviedo, 1995; Márquez Macías, Rosario: "La emigración española en el siglo XVIII a América”, en Rábida, N. 10, Huelva, 1991, págs. 68-79; y Márquez Macías, Rosario: "La emigración gallega a América en la época del comercio libre (1765-1824)", en Revista da Comisión Galega do Quinto Centenario, N. ${ }^{\circ} 4$, Santiago de Compostela, 1989, págs. 37-56.

6 Ver como ejemplos los trabajos contenidos en los números 6 y 7 de la Revista da Comisión Galega do Quinto Centenario, de 1989 y 1990, respectivamente. Véase también Eiras Roel, Antonio: "Informe sobre el censo de 1787 como fuente para el estudio comarcalizado de la emigración gallega”, en Revista da Comisión Galega do Quinto Centenario, N. ${ }^{\circ}$ 4, Santiago de Compostela, 1989, págs. 157-175.

7 Ibídem, págs. 171-173; Eiras Roel, Antonio: "La emigración gallega a América. Panorama General”, en Eiras Roel, Antonio (ed.): La emigración española a Ultramar, 1492-1914, Ediciones Tabapress, Madrid, 1991, págs. 23 y 24; Barreiro Mallón, Baudilio: "Ritmo, causas y consecuencias de la emigración asturiana a América, 1700-1850”, en Eiras Roel, Antonio (ed.): La emigración española ..., pág. 43; De Cristóforis, Nadia Andrea: Las migraciones de gallegos y asturianos a Buenos Aires, 1770-1860, Tesis doctoral inédita, Universidad de Buenos Aires, 2005, págs. 70-81. 
tancia que tuvieron lugar dentro de Asturias se originaron en las zonas más montañosas y más pobres, es decir en los concejos de la porción meridional o central del Principado, y se articularon de modos variables con las migraciones transoceánicas. ${ }^{8}$

Algunos estudios que se concentraron en distintos contextos de recepción de los flujos astur-galaicos transoceánicos de fines de la etapa moderna permitieron una aproximación más precisa a los volúmenes alcanzados por estas corrientes. En el caso de los desplazamientos que se dirigieron a Buenos Aires, por ejemplo, disponemos de algunas cifras de los stocks migratorios, que dan cuenta del incremento de la presencia de los gallegos y asturianos, dentro de la sociedad porteña tardo colonial. Según el padrón de habitantes de Buenos Aires de 1744, para esta fecha había en la ciudad alrededor de 36 gallegos y 8 asturianos. ${ }^{9}$ Hacia 1810 los oriundos de Galicia eran más de 795, mientras que los naturales del Principado superaban los $134 .{ }^{10}$ En esta última coyuntura los gallegos se convirtieron en el principal grupo peninsular, desde un punto de vista regional. ${ }^{11}$ Detrás de ellos se ubicaban los andaluces, vascos, catalanes, castellanos y asturianos, en orden decreciente.

8 Ansón Calvo, María Carmen: "Movimientos migratorios ...”, pág. 463.

9 Facultad de Filosofía y Letras: Documentos para la Historia Argentina, Tomo X, Padrones de la ciudad y campaña de Buenos Aires (1726-1810), Peuser, Buenos Aires, 1920, págs. 328-506. Debemos señalar que probablemente el número de gallegos y asturianos en el Buenos Aires de mediados del siglo XVIII fue mayor. Las cifras que brindamos son mínimas y provisorias, debido a que existen problemas de subregistro de los migrantes del noroeste hispánico en el padrón de 1744 (en algunos casos no se especificaron las procedencias regionales de los españoles).

10 Estas últimas cifras se obtuvieron a partir del tratamiento complementario de los padrones de habitantes de Buenos Aires de 1806, 1807 y 1810. Véase Archivo General de la Nación (en adelante, AGN), Gobierno Colonial, Padrones Generales de los habitantes de Buenos Aires de 1806 y 1807 , IX 9-7-7; y Censo de Buenos Aires de 1810, IX 10-7-1. Debemos subrayar que a partir de la documentación empleada se infravalora el número de migrantes del noroeste hispánico, debido a dos motivos básicos: por una parte, los padrones de 1806, 1807 y 1810 no han llegado completos hasta nuestros días: algunos de sus cuarteles o barrios se han perdido o no se han podido localizar. Por lo tanto, nuestro análisis se limitó a dieciséis cuarteles de los veinte en que entonces se dividía la ciudad (1, 2, 3, 4, 5, 6, 7, $8,11,12,13,14,15,17,18,19)$. Por otra parte, en muchos casos en las fuentes utilizadas se han omitido las procedencias regionales de los españoles (que pueden figurar como "peninsulares", "españoles-europeos", o simplemente, como "españoles"). De allí que en nuestra contabilización probablemente falten algunos gallegos y asturianos que aparecían con estas últimas denominaciones.

11 AGN, Andrés Lamas, 35, N. ${ }^{\text {o } 2638 . ~ P e d r o ~ A n t o n i o ~ C e r v i n ̃ o ~ l l e g o ́ ~ a ~ a f i r m a r ~ q u e ~ " C o m o ~ l o s ~}$ naturales del Reino de Galicia, habitantes en esta capital [la de Buenos Aires] son en mayor número que los de las demás Provincias de España, respectivamente, por esta misma razón, tienen la satisfacción honrosa de que contribuyeron más que otra alguna a la gloriosa reconquista de ella". Véase Castro López, Manuel: El Tercio de Galicia en la defensa de Buenos Aires: documentos inéditos, Ortega y Radaelli, Buenos Aires, 1911, pág. 5. 
Algunos testimonios de contemporáneos aludieron al incremento de los flujos españoles (en especial, de la porción septentrional de la Península) hacia la América austral, haciendo hincapié en los variados mecanismos ilegales que ponían en marcha los migrantes con el fin de realizar el traslado ultramarino:

A pelotones salen los muchachos de Galicia, Vizcaya Montañas, Asturias, Castilla, y mas Reynos, y Provincias de España para pasar a Buenos -Ayres, que en calidad de Polizones se embarcan en los buques de Guerra, correos marítimos, y embarcaciones particulares, de forma que aturde los que llegan a Montevideo, y aún los que sin saltar allí en tierra se transbordan a las lanchas que pasan a Buenos -Ayres. De los criados de los oficiales de la Armada es muy singular el que vuelve a España, porque ya salen con la mira de quedarse y aunque alguno pueda no tener esa intención en la navegación la forma, y mas si ha tenido algún contratiempo, o disgusto, que dudo el que le falte. ${ }^{12}$

En síntesis, distintos tipos de estudios, de ambos lados del océano, han puesto de relieve, a través de documentación más o menos directa, la creciente participación de los flujos astur-galaicos en las corrientes de españoles hacia el exterior. Los movimientos de larga distancia hacia el Continente Americano coexistieron con los intrapeninsulares, tanto a un nivel inter como intra-regional. Éstos últimos, de carácter más tradicional, aportaron a las comunidades del noroeste hispánico una importante experiencia sobre las implicaciones de migrar, que pudo favorecer de distintos modos las partidas hacia las Indias.

\section{Las interpretaciones de los contemporáneos sobre los fenómenos migratorios}

Los testigos que presenciaron las migraciones de gallegos y asturianos en las postrimerías de la etapa moderna atribuyeron dichos desplazamientos a diferentes motivos. Por un lado, aludieron al problema de la falta de trabajo en general, aspecto que estimulaba a los jóvenes a buscar empleo en otras provincias peninsulares o en el exterior. Por otro lado, hicieron referencia a la cuestión del exceso de población, en especial, el producido desde el siglo XVIII, en un contexto de creciente escasez de medios de subsistencia. Por último, pusieron el acento en la desigual dis-

12 AGN, Biblioteca Nacional (en adelante, BN), Patagonia. Documentos del Archivo de Indias, "Breve descripción de las circunstancias en que se halla la Provincia de Buenos Aires, e Islas Malvinas y el modo fácil de reparar la imperfección de su actualidad”, 196, 1778, fols. 8 y 9. 
tribución de la tierra, es decir, en las características de la estructura agraria del noroeste español, de la que dependía económicamente la mayoría de sus habitantes. Muchas veces, estos factores aparecieron combinados, dentro de un cuadro explicativo mayor. Sin embargo, nos detendremos brevemente en ellos por separado, por razones analíticas. ${ }^{13}$

La falta de trabajos "útiles" fue una razón de peso para dar cuenta de la salida de población desde el noroeste hispánico. Sobre este particular se pronunció la Junta del Reino de Galicia, al solicitar al gobierno la concesión del monopolio del comercio con el Mar del Sur. La Junta sostenía que esto último era viable en virtud de una serie de condiciones favorables, entre los que se encontraba la abundante mano de obra existente en Galicia, que podría convertirla en un verdadero centro manufacturero. La prueba de la existencia de esa potencial fuerza de trabajo estaba dada por la "salida de mas de 40 mil hombres que ban a buscar fuera del Reyno su subsistencia y que no se apartarían de sus casas, si se les proporcionase empleo en ellas". ${ }^{14}$ En opinión de la Junta: "las Fabricas de Sombreros, las Tenerias, los Texidos de algodón, la fundicion de cañones de Bronce, y todo genero de vasos de cobre son los quatro obgetos mas ovios para radicar en el Pais estos Vagos, y un fecundo manantial de riquezas para la Nacion". ${ }^{15}$ Tal como queda expresado, la solución para impedir la salida de población consistía en generar empleos que permitieran fijar a los habitantes a su terruño.

El reformista ilustrado Pedro Rodríguez Campomanes sostuvo una idea bastante similar a la expuesta. En su Informe sobre la emigración de gallegos a Portugal argumentó que los pobres jornaleros del Reino "por no encontrar en qué ocuparse se difunden no sólo en Portugal, sino en el resto de España". ${ }^{16}$ También agregaba que en el país vecino los españoles del

13 Para un examen global del pensamiento de los contemporáneos (en especial, los ilustrados gallegos) sobre la emigración, v. Meijide Pardo, Antonio: La emigración gallega ..., págs. 103-121; Artaza Montero, Manuel María de: "Los ilustrados gallegos y el problema de la emigración”, en Revista da Comisión Galega do Quinto Centenario, N. 7 , Santiago de Compostela, 1990, págs. 192-195; Bianchi, Diana: "La visión ilustrada del pauperismo en la Galicia del siglo XVIII", en Anuario del Centro de Estudios Gallegos, Universidad de la República, Facultad de Humanidades y Ciencias de la Educación, Montevideo, 1998, págs. 68-73.

14 Archivo Municipal de La Coruña (en adelante, AMC), Junta del Reyno, 1775, 22, "Representación del Reino de Galicia a S. M. para el comercio desde La Coruña al Mar de el Sur".

15 Ibídem.

16 Rodríguez Campomanes, Pedro: "Informe original del Conde de Campomanes sobre la emigración a Portugal de los habitantes de Galicia, y el papel que el Marqués de Croix escribió en diciembre de 1764 con dicho motivo", en Castro, Manuel de: "Informe de Campomanes sobre la emigración e industrialización de Galicia”, en Cuadernos de Estudios Gallegos, T. XIII, N. o 40, 1958, pág. 247. 
noroeste hispánico encontraban ciertos beneficios: “en Lisboa, por el gran comercio de aquel puerto, hallan facilidad los Gallegos de ganar su jornal mayor que en Galicia. Esta ganancia o ventaja de utilidad es la que llama a Portugal". ${ }^{17}$ A ello se sumaba el hecho de que una vez traspasadas las fronteras del país limítrofe, los migrantes lograban evadirse de las obligaciones militares.

El exceso de población se ponía en relación con la falta de empleos en general, en una concepción donde el primer fenómeno se hacía visible por la imposibilidad de muchos peninsulares de encontrar una ocupación rentable. Como afirmaba Campomanes: "Galicia está muy poblada y tiene a la verdad sobra de habitantes en el estado actual, porque carece de artes, de comercio y de navegación en que exercitarse". ${ }^{18}$ Otra importante figura de la época, José Andrés Cornide, compartió esta visión. En sus “Observaciones sobre el establecimiento de colonias en las provincias del Río de la Plata", elaboradas con motivo del proyecto de la monarquía española de enviar familias pobladoras a la América austral, el mencionado político de origen coruñés razonaba del siguiente modo:

En esta Provincia [suponemos que se trata de la antigua Provincia de Santiago], como en muchas de los climas septentrionales, es muy numerosa la población por la extrema fecundidad de sus mujeres, por la calidad de los alimentos, por la proximidad de la mar y por la templanza de las estaciones [...] Compárese pues esta extraordinaria fecundidad con la pobreza que llevo indicada y que resultará que en Galicia deben quedar infructíferas muchas de sus producciones por falta de conveniencias en sus padres para establecerlas y por falta de terrenos a propósito en que establecerse; y, aún habiendo estos, por falta de facultades para descuajarlos y por recelo de que su corto rédito (reducidas las pensiones) a penas costée las labores de cultivarlos. De esta imposibilidad para la subsistencia es efecto la continua salida de los gallegos celibatos y casados a Castilla y Portugal, que anualmente ascenderá a más de 50 mil personas [sic]. ${ }^{19}$

No sólo en relación con las emigraciones gallegas se mantuvieron ideas como las que acabamos de mencionar, sino que también en vinculación con las salidas desde el Principado de Asturias se llegaron a defender tales posturas. En la percepción del político y escritor gijonés, Gaspar Melchor de Jovellanos, la emigración intrapeninsular asturiana estaba liga-

17 Ibídem.

18 Ibídem, págs. 248 y 249.

19 Cornide, José: "Observaciones sobre el establecimiento de colonias en las Provincias del Río de la Plata, Paraguay y Tucumán”, en Apolant, Juan Alejandro: Un predicador en el desierto. Un manuscrito ignorado de José Cornide, Ediciones del Patronato de Cultura Gallega, Montevideo, 1970, pág. 23. 
da a un desequilibrio entre la cantidad de habitantes y los recursos disponibles. De este modo, aclaraba: "yo miro estas colonias de emigrantes que pasan los montes y se derraman a buscar su vida por toda la Península, como una exacta medida del sobrante de su población". ${ }^{20}$ Los que salían lo hacían para poder subsistir, por razones de fuerza mayor. En esta misma línea de pensamiento, y de modo sugestivo, Cornide sostuvo que la expatriación voluntaria de gallegos no constituía un "vicio", como muchos contemporáneos creían, sino una verdadera "necesidad". ${ }^{21}$

Para la Junta General del Principado, el aumento de población era el responsable indirecto de la emigración. Según dicha institución, el primer fenómeno había conducido a una subdivisión de la tierra, y como esta última no garantizaba el alimento de todos los miembros de la familia, algunos de sus integrantes se habían visto en la necesidad de partir del suelo natal. ${ }^{22}$ En los informes que los diferentes corresponsales elevaron al geógrafo Tomás López, desde distintos puntos de Asturias, también se vinculaba la situación de miseria, con el exceso de población. Los encargados de elaborar las respuestas al interrogatorio propuesto, en el Concejo occidental de San Tirso de Abres, afirmaban que había "mucha pobreza por mucha gente en mucho terreno", por ejemplo. ${ }^{23}$

Sin embargo, algunas personalidades de la época relativizaron la idea de que la sobrepoblación se encontrara en el origen de la emigración gallega en particular, y enfatizaron el móvil de la pobreza, que empujaba a los labradores de buen vivir a "redimir las urgencias de sus familias" en tierras castellanas, andaluzas o portuguesas. ${ }^{24}$ Asimismo, otros consideraron que no era la pobreza la causa de la partida de los gallegos, sino una particular estructura agraria, que no garantizaba la supervivencia de todos por igual. En relación con la cuestión de la desigual distribución de la tierra, los argumentos tendieron a remarcar, por un lado, la concentración de la misma en manos de los mayorazgos, monasterios e iglesias, y por otro lado, su exce-

20 Jovellanos, Gaspar Melchor de: Cartas del Viaje de Asturias (Cartas a Ponz), T. 2, Ediciones Ayalga, Asturias, 1981, págs. 19-21.

21 Cornide, José: "Observaciones sobre el establecimiento...", pág. 23.

22 Barreiro Mallón, Baudilio: "Movimientos migratorios en Asturias y Cantabria. Siglos XVI al XX”, en Eiras Roel, Antonio y Rey Castelao, Ofelia (eds.): Migraciones internas ..., pág. 133.

23 Merinero, María Jesús y Barrientos, Gonzalo: Asturias según los asturianos del último setecientos (Respuestas al interrogatorio de Tomás López), Servicio de Publicaciones del Principado de Asturias, Oviedo, 1992, pág. 270.

24 Archivo del Reino de Galicia (en adelante, ARG), Papeles de Cornide, 5-97, "Representación hecha el 9 de enero de 1768 al Consejo de Castilla por el Intendente del Reino de Galicia Marqués de Piedrabuena sobre la cultura de los montes abiertos de este Reino". 
siva subdivisión. ${ }^{25}$ Según la "Sociedad Económica de Amigos del País de Asturias", esta última situación había conducido a una progresiva pauperización del campesinado, que ya no se podía mantener dentro de las pequeñas extensiones de tierra que poseía. ${ }^{26}$

Para finalizar, pondríamos de relieve que en nuestra opinión, los argumentos sobre el exceso de población, la falta de ocupaciones o la desigual distribución de la tierra, esgrimidos en las postrimerías de la etapa moderna, para explicar la partida de gallegos y asturianos, han encontrado un lugar en las actuales interpretaciones sobre los procesos migratorios desde el noroeste español. Tengamos presente que estas últimas terminaron otorgando una gran importancia a los factores de tipo demográfico (presión de la sobrepoblación) o socio-económico (incidencia de las crisis económicas), ${ }^{27}$ recuperando de algún modo aquellas percepciones forjadas por quienes presenciaron los movimientos espaciales de corta, media o larga distancia, a fines del Antiguo Régimen.

\section{Las tensiones entre las ideas de restringir y fomentar la emigración}

Desde los primeros tiempos de la conquista y colonización, la corona española se preocupó por controlar la salida de peninsulares al Continente Americano. En 1503, la fundación de la Casa de Contratación en Sevilla

25 Para una clara exposición de estos dos fenómenos, véase Jovellanos, Gaspar Melchor de: Cartas del Viaje ..., T. 1, págs. 145-156. Sobre el primer aspecto mencionado, consultar las impresiones de un viajero como Alexandre de Laborde en Garrido, Gustavo A.: Aventureiros e curiosos. Relatos de viaxeiros estranxeiros por Galicia. Séculos XV-XX, Ed. Galaxia, Vigo, 1994, pág. 244.

26 Sociedad Económica de Amigos del País de Asturias: "Informe sobre las causas de la decadencia de la ganadería en Asturias y medios de mejorarla”, en Memorias de la Sociedad Económica de Amigos del País de Asturias. Agricultura, Industria y Comercio, Edición facsimilar de la Biblioteca Antigua Asturiana, Gijón, 1982, pág. 23.

27 Para examinar los interpretaciones que hicieron hincapié en cuestiones de índole demográfica, véase para el caso gallego: Eiras Roel, Antonio y Rey Castelao, Ofelia: Los gallegos..., págs. 155-159; o Artaza Montero, Manuel María de: “Los ilustrados gallegos...”, págs. 189-191. Para el caso asturiano, véase: Rodríguez, Jesús Jerónimo: Asturias..., págs. 62-63; Ansón Calvo, María Carmen: "La emigración asturiana en el siglo XVIII. Notas para su estudio", en Eiras Roel, Antonio (ed.), La emigración española..., pág. 84; Anes Álvarez, Rafael: La emigración de asturianos..., pág. 38, entre otros. Los trabajos que pusieron el acento en los motivos de tipo socio-económico fueron: para el caso gallego, Eiras Roel, Antonio: "La emigración gallega...”, págs. 27, 31-34; o Fernández Cortizo, Camilo: "Galicia en el Antiguo Régimen", en AAVV, Galicia y América. Cinco siglos de historia, Xunta de Galicia, Consello da Cultura Galega, sin folio, págs. 20-22; y para el caso asturiano, Ojeda, Germán y San Miguel, José Luis: Campesinos, emigrantes, indianos. Emigración y Economía en Asturias, 1830-1930, Ayalga Ediciones, Gijón, 1985, págs. 60-61; Rodríguez, Jesús Jerónimo: Asturias..., págs. 62-64; y Ansón Calvo, María Carmen: “La emigración asturiana...”, págs. 83-84, entre otros. 
fue la ocasión para proceder a una primera sistematización de la normativa que debía regular el pasaje de personas a Indias, y su establecimiento en las mismas. Una de las más importantes medidas adoptadas fue la obligación de obtener un permiso de la Casa, como condición para embarcarse a los dominios de ultramar. ${ }^{28}$ Con el paso del tiempo, la documentación requerida para obtener dichas licencias se fue multiplicando, lo que dificultaba su tramitación. ${ }^{29}$

Hacia fines del siglo XVIII, la política de control sobre los movimientos de personas y bienes se intensificó. ${ }^{30} \mathrm{El}$ "Reglamento y Aranceles reales para el Comercio Libre de España a Indias", sancionado el 12 de octubre de 1778, se ocupó de regular el traslado transatlántico de pasajeros y mercancías hasta el año 1827. La obligatoriedad de poseer la licencia para embarcarse y las precauciones para que esta prescripción se respetara, quedaron estipuladas claramente en el artículo $10 .^{\circ}$ del mencionado Reglamento:

Después de entregados los Registros, que deben darse cerrados y sellados con dirección a los Ministerios Reales de los Puertos de América, y pasadas las copias de ellos a los Jueces de Arribadas, irán estos a bordo de las Embarcaciones para entregar a sus Capitanes, o Patrones mi Real Patente de Navegación despachada por el Ministerio de Indias, de que siempre tienen un número competente de repuesto, y entonces practicarán la Revista acostumbrada de la Tripulación, Cargadores, y Pasajeros, a fin de no vayan Polizones, ni se embarque persona alguna sin licencia mía despachada por la Vía Reservada de Indias, del Consejo Supremo de ellas, o de la Real Audiencia de Contratación en Cádiz, que también puede darlas en los casos prefinidos por las Leyes. ${ }^{31}$

28 Recopilación de Leyes de los Reinos de Indias, Edición facsimilar, Madrid, 1943, T. III, L. VIII, Título XXVI, Ley j, "Que ningún natural, ni extranjero pase a las Indias sin licencia del Rey, ó de la Casa de Sevilla, en los casos que la pudiere dar".

29 Los expedientes completos que se conservan en el Archivo General de Indias (en adelante, AGI) para el siglo XVIII, por ejemplo, contienen las siguientes piezas: a) la solicitud del presunto emigrante, b) nota o registro de la presentación de la misma, c) copia de la norma que autorizaba la emigración, d) concesión de la licencia de embarque por los oficiales de la Casa de la Contratación, e) "información" sobre la limpieza de sangre del solicitante, f) autorización de la esposa, cuando el solicitante era casado y viajaba solo, g) anotación de haberse efectuado el embarque, h) anotación de tipo contable de haberse pagado el importe de la licencia e i) cartas de familiares instalados en América reclamando al solicitante.

30 Delgado Ribas, Josep: "La emigración española a América Latina durante la época del comercio libre (1765-1820). El ejemplo catalán”, en Boletín Americanista, Vol. XXIV, N. ${ }^{\circ} 32$, Barcelona, 1982, págs. 120-121; Yáñez Gallardo, César: Saltar con red. La temprana emigración catalana a América. Ca. 1830-1870, Alianza, Madrid, 1996, págs. 26-27.

31 Art. 10. ${ }^{\circ}$, "Reglamento y Aranceles reales para el Comercio Libre de España a Indias", en Facultad de Filosofía y Letras: Documentos para la Historia Argentina, T. VI, Comercio de Indias. Comercio Libre (1778-1791), Buenos Aires, 1915, pág. 18. 
Al mismo tiempo, el artículo 11..$^{\circ}$ era explícito en relación con el tratamiento que debía dispensarse a todos aquellos que no cumplieran con la obligación de poseer el permiso para embarcarse: debían ser reconducidos en calidad de "presos" a España, junto con los capitanes o patrones del barco, para ser sometidos a las penas correspondientes a su delito. ${ }^{32} \mathrm{El}$ aumento del control conllevó una especificación de las categorías de personas que se podían trasladar a Indias: la "tripulación", los "cargadores" y los "pasajeros" (como puede apreciarse en el artículo 10. ${ }^{\circ}$, ya citado).

Las opiniones de algunos pensadores ligados directa o indirectamente a la monarquía borbónica avalaron la idea de la necesidad de restringir los flujos humanos que salían para el exterior. En este sentido, tengamos presente que figuras como Juan Amor de Soria, el Padre Sarmiento o el Marqués de Croix llegaron a manifestarse a favor de la implementación de medidas coercitivas para frenar el "drenaje" de población del suelo español. Estas últimas iban desde la estipulación de la prohibición, hasta el llamado a una férrea acción estatal destinada a limitar la movilidad de la población campesina, o la confiscación de los bienes de aquellos que abandonaran su tierra de naturaleza o de vecindad. ${ }^{33}$ La Junta del Reino de Galicia actuó como "caja de resonancia" de este tipo de planteos. La mayoría de sus miembros consideraba que la emigración había convertido a Galicia en el Reino "más menesteroso y necesitado dentro de España", pues en ausencia de los varones, las familias pasaban hambrunas y no podían pagar sus tributos. El remedio sugerido para evitar este mal era la total inhibición de los desplazamientos humanos, bajo la pena de las más severas sanciones. ${ }^{34}$

Sin embargo, debemos destacar que a fines del setecientos, la política de control y restricción defendida por la corona y por ciertos círculos de intelectuales y políticos, coexistió con otra, de abierto estímulo al traslado de españoles a los dominios de ultramar, con fines colonizadores. Esta iniciativa oficial "pobladora" también encontró importantes justificaciones en las ideas de algunas instituciones y pensadores ilustrados de la época, quienes comenzaron a insistir en las ventajas que podía traer la emigración para

32 Art. 11. ${ }^{\circ}$ Ibídem, págs. 18-19.

33 Rodríguez, Manuel Martín: Pensamiento económico..., págs. 158-160; Saurín de la Iglesia, María Rosa: "La emigración a Indias entre Ilustración y Liberalismo", en Estudios Dieciochistas en homenaje al Profesor José Miguel Caso González, Vol. II, Oviedo, 1995, págs. 307-309; Castro, Manuel de: "Informe de Campomanes ...", págs. 242-243.

34 Eiras Roel, Antonio y Rey Castelao, Ofelia: Los gallegos..., pág. 160; y Artaza Montero, Manuel María de: "Los ilustrados gallegos ...”, pág. 192. 
la España borbónica. Tanto José Somoza como Francisco Somoza de Monsoriú, por ejemplo, mantuvieron que las salidas de los labradores, provocadas por su estado de pobreza, favorecían a la larga la convivencia general del Reino. Esto último se debía a que gracias a los desplazamientos hacia el exterior, los trabajadores lograban acumular un pequeño capital, con el cual podían "pagar las pensiones de sus haciendas, redimir los cuerpos de la intemperie, ofrecer al monarca sus tributos, comprar los instrumentos de agricultura y dedicarse a un pequeño comercio de ganado". ${ }^{35}$ Gaspar Melchor de Jovellanos, si bien reconocía los inconvenientes que traían las emigraciones, se inclinaba por destacar sus consecuencias positivas. En este sentido, hacía hincapié en el valor de las remesas como generadoras de riquezas para el país, o destacaba la capacidad de dichos desplazamientos para transformar las "sencillas e inocentes" costumbres

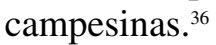

De esta manera, poco a poco fue cobrando fuerza el proyecto de formar colonias de peninsulares dentro y fuera de España, con el objeto de mejorar el nivel de vida de los más necesitados, y de poblar los dominios de la monarquía sobre los que no se había logrado un férreo control. Ya antes de mediados del siglo XVIII, Benito Jerónimo Feijóo, una de las personalidades más representativas de la primera generación de ilustrados, había sugerido la posibilidad de trasladar gente pobre de Galicia a diferentes colonias dentro de España, para que cultivaran las tierras incultas. ${ }^{37}$ Esta propuesta tuvo un amplio eco, hasta tal punto que hacia 1844, la "Sociedad Económica de Amigos del País de Asturias" seguía insistiendo en los beneficios de un "bien entendido sistema de colonización" para ocupar a la numerosa población y "descargar la agricultura y ganadería de brazos inútiles que gravitan sobre ellas". ${ }^{38}$

También se argumentó a favor de la formación de asentamientos de peninsulares fuera de España. Pedro Rodríguez Campomanes vio en estos últimos un medio de regenerar a los mal entretenidos y de poblar zonas deshabitadas..$^{39}$ A diferencia de lo que opinaban Juan Amor de Soria, el

35 ARG, Papeles de Cornide, 5-86/1, "Discurso de el Capitán Don Joseph Antonio de Somoza y Monsoriú sobre la cultura de los Montes para el día 22 de marzo de 1767”; Eiras Roel, Antonio y Rey Castelao, Ofelia: Los gallegos..., págs. 161-162.

36 Jovellanos, Gaspar Melchor de: Cartas del Viaje ..., T. 2, págs. 21 y 22.

37 Feijóo, Benito Jerónimo: Teatro Crítico Universal, Vol. III, Ediciones de "La Lectura", Madrid, 1925, pág. 319.

38 Sociedad Económica de Amigos del País de Asturias: "Informe sobre las causas ...,, pág. 54.

39 Rodríguez Campomanes, Pedro: "Informe original...”, pág. 252. 
Padre Sarmiento o el Marqués de Croix, Campomanes no creía que los problemas de España se solucionarían impidiendo coercitivamente la salida de peninsulares. En su opinión, la sanción de una ley anti-emigratoria, como la propuesta por el Capitán General de Galicia, no tenía sentido. En un plano ideal, lo prioritario era crear nuevas fuentes de trabajo, para que los potenciales migrantes no tuvieran necesidad de abandonar su suelo natal. En esta dirección, había que comenzar por reactivar la economía, mediante el fomento de la pesca, el libre comercio y la industrialización. Sin embargo, mientras no existieran estas últimas condiciones, la emigración no debía ser concebida de manera totalmente negativa: había que entender que la misma podía conllevar algunos efectos positivos, al contribuir a erradicar la pobreza, entre otras cuestiones. Las salidas de gallegos a Portugal, por ejemplo, no sólo aliviaban las cargas del Estado, sino que también favorecían el crecimiento de la economía española, cuando los que habían partido retornaban con sus ahorros. ${ }^{40}$

La concepción de las Indias como un espacio de poblamiento no era por cierto novedosa: tengamos presente que había alimentado las políticas colonizadoras desde comienzos del siglo XVI. Sin embargo, a lo largo del setecientos, las campañas de reclutamiento comenzaron a ser valoradas porque se creía que podían satisfacer algunos objetivos perentorios de la monarquía, tales como asegurar las fronteras en los dominios ultramarinos, reivindicar territorios en litigio, o desarrollar áreas deprimidas para incorporarlas a la economía metropolitana ${ }^{41}$ Hacia 1778 José Cornide justificaba el proyecto borbónico de poblamiento y daba algunas ideas acerca de cómo llevarlo a cabo. Entre otras cuestiones, el político coruñés estaba convencido de que "la América debe considerarse bajo varios aspectos, esto es: en cuanto puede dar consumo a nuestros frutos y ropas, en cuanto puede proveernos de los de su cosecha y en cuanto es una parte considerable de la monarquía" ${ }^{42}$ Por ello, los establecimientos en dicho continente debían ser concebidos como sumamente necesarios. ${ }^{43}$

El colono español en ultramar aparecía entonces como actor principal de la política de defensa del imperio y como motor de la reactivación económica que podía beneficiar a la metrópoli. En este sentido, un informe

40 Ibídem, págs. 246, 249-252.

41 Martínez Shaw, Carlos: La emigración española a América (1492-1824), (Colección

"Cruzar el Charco"), Fundación Archivo de Indianos, Colombres, 1994, págs. 42-43.

42 Cornide, José: "Observaciones sobre el establecimiento ...", pág. 17.

43 Ibídem, pág. 18. 
anónimo del mismo año que el de Cornide, alentaba la idea de trasladar familias de españoles a los puertos de San Julián, Santa Elena, Bahía sin Fondo y Puerto Deseado, que estaban "clamando por habitantes". De este modo, se podrían evitar las amenazas y hostilidades que esos parajes recibían constantemente de los enemigos de la corona. Incluso, se proponía enviar a los negros libres (solteros y casados) al establecimiento de las Islas Malvinas, para reemplazar a las tropas reales allí instaladas. Estas últimas podrían ser utilizadas para cubrir puertos que estaban desguarnecidos y que eran vulnerables a los ataques extranjeros. ${ }^{44}$

La obsesión, bastante generalizada en la época, de ver "adelantada" (es decir, aumentada) la población en América, condujo a José del Campillo y Cosío a sugerir que se podía transportar a dicho continente a una "porción de gente española" que "no solamente no haría falta ninguna en el Reyno, sino que sería conocida ventaja para él limpiar el Estado enteramente de ellas". En este sentido, proponía enviar a ultramar a los gitanos, facinerosos, "mujeres públicas e incorregibles". De los últimos grupos afirmaba que si se los mandaba a Indias, sus miembros se casarían y se "harían gente de bien", sacándose de ello "mucho provecho". ${ }^{45}$

Si bien el proyecto de Campillo y Cosío no llegó a llevarse a la práctica, pues sus medios contradecían algunos de los lineamientos de la política emigratoria de la monarquía (recordemos que esta última se había inclinado por una lógica de selección que únicamente favorecía el pasaje de "cristianos" de "buenas costumbres"), tanto las autoridades metropolitanas como las indianas fomentaron la organización de campañas de reclutamiento, para poblar diferentes áreas de los territorios americanos. Los colonos elegidos para estas empresas fueron los originarios del norte español y de las Islas Canarias. Hacia 1724-1725 el gobernador de Buenos Aires, Bruno Zabala, auspició un proyecto para trasladar 25 familias gallegas y otras tantas canarias a la ciudad de Montevideo. La operación, aprobada por la corona, terminó confiada exclusivamente a los pobladores insulares. Los oriundos del Reino de Galicia participaron en otras tres empresas, que fracasaron o tuvieron un éxito muy limitado: la de La Española, en 1767; la del Río de la Plata, de 1778 a 1784; y la de la costa de los Mosquitos, en

44 AGN, Biblioteca Nacional, Patagonia. Documentos del Archivo de Indias, "Breve descripción de las circunstancias en que se halla la Provincia de Buenos Aires, e Islas Malvinas y el modo fácil de reparar la imperfección de su actualidad", 196, 1778, fols. 13-18.

45 Campillo y Cosio, José del: Nuevo sistema de gobierno económico para la América, Grupo Ed. Asturiano, Oviedo, 1993, págs. 285-287. 
1787..$^{46}$ Insistiremos en que el objetivo de estas campañas era poblar áreas amenazadas por la presencia extranjera, es decir, fundar asentamientos estables de colonos fieles a la corona, en espacios estratégicos. ${ }^{47} \mathrm{~A}$ continuación nos detendremos en algunos pormenores de las expediciones al Río de la Plata, por constituir un ejemplo de emigración dirigida, en la que participaron no sólo los gallegos, como acabamos de aclarar, sino también los asturianos y castellano-leoneses. ${ }^{48}$

\section{Los instrumentos de las políticas de poblamiento en la América austral: las campañas de colonos y el ejército}

La empresa destinada al Río de la Plata fue en gran medida preventiva: buscaba evitar que los ingleses pudieran penetrar en la región patagónica, desafiando el poder español establecido en la porción austral del continente. ${ }^{49}$ Como rezaba un informe anónimo de 1778 :

46 Es interesante hacer notar que, aún cuando era evidente la frustración del proyecto poblador del Río de la Plata, la monarquía española continuó promoviendo la organización de una nueva campaña, con los mismos fines que la anterior, con destino a la costa de los Mosquitos. Hacia el año 1787, un artículo aparecido en el Correo de los Ciegos seguía sosteniendo la idea de que este tipo de empresa era "una oportunidad incomparable para el proletariado del norte de España", el cual podía encontrar su "felicidad" en tierras ultramarinas. Véase Correo de los Ciegos, N. ${ }^{\circ}$ 99, 26 de septiembre de 1787, pág. 442.

47 Eiras Roel, Antonio y Rey Castelao, Ofelia: Los gallegos..., págs. 163-165; Martínez Shaw, Carlos: La emigración española ..., págs. 207-213; Rey Castelao, Ofelia: "Los gallegos ...”, págs. 3440. Para el caso de la expedición al Río de la Plata en particular, ver especialmente el ya clásico libro de Apolant, Juan Alejandro: Operativo Patagonia. Historia de la mayor aportación demográfica masiva a la Banda Oriental, Montevideo, 1970; la prolija obra de Porro Gutiérrez, Jesús María: La emigración asturiana y castellano-leonesa para el poblamiento de la Patagonia en época de Carlos III, SeverCuesta, Valladolid, 1995; o los otros siguientes trabajos: Cuesta, Luisa: "La emigración gallega a América", en Arquivos do Seminario de Estudos Galegos, IV, Santiago de Compostela, 1932, págs. 170-176; Longo González, Natalia: "Expedición de familias al Río de la Plata (1778-83). Presupuestos ideológicos", en Revista da Comisión Galega do Quinto Centenario, N. ${ }^{\circ}$ 2, Santiago de Compostela, 1989, págs. 39-56; Vilanova Rodríguez, Alberto: Los gallegos en la Argentina, Vol. I, Ediciones Galicia, Argentina, 1966, págs. 178-206; o Rodríguez Galdo, María Xosé: Galicia, país de emigración. La emigración gallega a América hasta 1930, (Colección “Cruzar el Charco”), Fundación Archivo de Indianos, Colombres, 1993, págs. 31-38, entre otros.

48 Algunas cuestiones administrativas vinculadas a estas campañas, sobre las que no haremos hincapié en los párrafos siguientes, por exceder los propósitos del presente artículo, pueden consultarse en AGN, Gobierno Colonial, Costa Patagónica, Documentos varios, IX 16-3-2, 1425; IX 16-3-3, 1426; IX 16-3-6, 1429; IX 16-5-1, 1448.

49 AGI, Audiencia de Buenos Aires, 328, Expedientes sobre familias pobladoras e incidencias en la Costa Patagónica, 1783-1791, fol. 2. 
Cualquier establecimiento que hagan [los ingleses] en las costas de la América Meridional, debe ser indefectiblemente muy perjudicial para la seguridad de los nuestros, y para nuestra navegación en aquellos mares, siendo de recelar se sitúen en algún paraje de la parte que corre desde el Río de la Plata hasta el estrecho de Magallanes, y aún en el estrecho mismo. Por consiguiente es de la mayor importancia procedamos sin pérdida de tiempo a ocupar allí algunos puntos esenciales que impidan cualquier tentativa, precaviendo los graves daños que se nos seguirán de que se adelantasen los ingleses a ocupar dichos puestos, desde donde interceptarían fácilmente nuestra navegación por el Cabo de Hornos, internándose en el Reino de Chile hasta invadir el Perú. ${ }^{50}$

La aparición del libro del Padre Falkner, Descripción de la Patagonia y de las partes contiguas de la América del Sur, hacia 1774, brindó información acerca de las pretensiones inglesas sobre la región, lo que parece haber influido en la decisión de la monarquía española de poner en marcha su operativo de poblamiento. ${ }^{51}$ Este último se anunció oficialmente a través de una Real Orden que el Secretario General del despacho de Indias, José de Gálvez, dio a conocer a Jorge Astraudi (encargado de la colectación y el envío de las familias):

En las Provincias del Río de la Plata serán muy convenientes algunas familias de España, que se hallen bien instruídas en todas las labores del campo, y otras faenas correspondientes a la mejor enseñanza de cosas domésticas, para que con su ejemplo pueda lograrse, que aquellos naturales lleguen a la perfección que se desea en todas las partes que componen un buen vecino del Pueblo. Por estas razones ha tenido el Rey por preciso se haga a V.S. el encargo de juntar algunas familias pobres de ese Reino, capaces de llenar aquel objeto, tratando con ellas los términos en que hayan de ir con sujeción al destino que quiera darles allá el Virrey de Buenos Aires, ofreciéndoles desde luego, que serán costeados por cuenta de S.M. en los Correos Marítimos que salen de este Puerto, lo que prevengo a V.S. de orden del Rey, para que proceda a su cumplimiento, dándome aviso de sus resultas, del número de las Familias que se presenten a hacer este viaje, y del de las personas de que se componga cada una. Dios guarde a V.S. ${ }^{52}$

50 AGN, BN, Patagonia. Documentos del Archivo de Indias, "Apuntes que se han tenido presentes para formalizar los que se han comunicado al Virrey con fecha de 8 de junio de 1778. Necesidad de formar dos Establecimientos con dos fuertes subalternos en las costas de América Meridional, e idea de la instrucción que se deberá dar a las personas comisionadas de llevar a efecto este pensamiento", 196, fols. 32-33.

51 Parish, Woodbine: Buenos Aires y las Provincias del Río de la Plata. Desde su descubrimiento y conquista por los españoles, Librería Hachette, Buenos Aires, sin folio, págs. 200-201; Apolant, Juan Alejandro: Un predicador ..., págs. 5 y 6; Porro Gutiérrez, Jesús María: La emigración asturiana..., págs. 10-11.

52 AMC, Cajas Río de la Plata, 1780, 1783-1792, "Carta circular mandada imprimir por Jorge Astraudi para darla a conocer en Galicia”, 29 de junio de 1778, sin catalogar. 
Como se puede apreciar, los fines estratégicos o defensivos no se explicitaban. Las expediciones a la América austral eran presentadas como una campaña moralizante o pedagógica, que encontraba en los labradores su mejor instrumento transformador. Tampoco se especificaba el destino final de los colonos, aunque la corona tenía en claro que deseaba enviarlos a la costa patagónica. Probablemente, se encubría parte del proyecto para no desalentar de antemano el reclutamiento de los potenciales emigrantes, que en última instancia, era voluntario.

Una vez comunicada la decisión de organizar la empresa pobladora en cuestión, se dieron a conocer las condiciones bajo las cuales se realizaría el traslado y el establecimiento allende el océano. Entre otras cuestiones, se estipuló lo siguiente: se enviarían 200 familias como máximo; se admitirían a paisanos y labradores, o artesanos de "oficios útiles" (herreros, carpinteros, albañiles, y otros semejantes); se daría preferencia a los casados sobre los solteros; los colonos serían transportados de cuenta de la Real Hacienda; se les daría en América habitaciones útiles para la labor y tierras en propiedad, una o dos yuntas para su beneficio, arados, semillas para sembrar y se los mantendría un año contado desde su instalación en los lugares a los que los destinara el virrey ${ }^{53}$ Por cada persona adulta embarcada, la Real Hacienda se comprometía a pagar 110 pesos fuertes; por las de dos a seis años, 108 pesos fuertes; mientras que por las menores de dos años, ninguna suma. Sabemos que en tiempos de guerra, los asentistas que habían hecho contrato con la corona para el transporte de las familias en cuestión, llegaron a lograr que el gobierno les abonara 150 pesos fuertes por pasajero, lo que pone de manifiesto que en torno a estas expediciones se fueron conformando fuertes intereses económicos, que lograron presionar exitosamente sobre el poder político, para obtener mayores beneficios del emprendimiento poblador. ${ }^{54}$ Sin embargo, más allá de la presencia de intermediadores en estas operaciones, como los asentistas mencionados, el responsable y garante último de las mismas fue el Estado español. Recordemos que un representante de este último, Jorge Astraudi, firmó personalmente todas las contratas con las personas que deseaban engan-

53 AGN, BN, Manuscritos copiados del Archivo de Indias, Real Orden, 19 de septiembre de 1778, 212, fols. 21-22; AMC, Cajas Río de la Plata, 1780, 1783-1792, "Condiciones del asiento, transporte y asistencia a las Familias pobladoras, aprobadas por el Rey", sin catalogar.

54 AGN, BN, Manuscritos copiados del Archivo de Indias, Real Orden, 3 de septiembre de 1779,212 , fols. 18 y 19 . 
charse en las expediciones, respaldando los compromisos adquiridos por la corona al respecto. ${ }^{55}$

A pesar de las previsiones adoptadas, la empresa pobladora no alcanzó los objetivos esperados. En los sucesivos embarques que se fueron organizando (llegaron a diez, de 1778 a 1784), la presencia de las familias gallegas, que eran las que inicialmente se buscaba captar, fue disminuyendo. De este modo, los contingentes tuvieron que completarse con asturianos y castellano-leoneses. Estos últimos fueron los que predominaron dentro del total de españoles que participaron en las expediciones en cuestión, llegando a representar el 41,7\% (855). Por detrás se ubicaron los asturianos, con un aporte del 33,1\% (678), y finalmente, los gallegos, con un 25,2\% (517). ${ }^{56}$ Algunos investigadores trataron de explicar los motivos por los cuales estos últimos peninsulares no se plegaron abiertamente al proyecto poblador. Por un lado, tanto Antonio Eiras Roel como Ofelia Rey Castelao y Jesús María Porro Gutiérrez mantuvieron que las expediciones no generaron mucho entusiasmo porque el traslado se presentaba como definitivo y de carácter familiar, lo que se distanciaba del modelo migratorio gallego más difundido, caracterizado por el desplazamiento individual y masculino, de tipo estacional o polianual. ${ }^{57}$ Por otro lado, Manuel María de Artaza Montero sostuvo que la débil respuesta de los labradores gallegos pareció deberse a la actitud del clero y de la hidalguía quienes, como buenos defensores de ideas anti-emigracionistas, convencieron a los potenciales colonos de los inconvenientes ligados al viaje ultramarino. ${ }^{58}$ Por último, María Rosa Saurín de la Iglesia puso de relieve la falacia con que la corona encubrió sus designios estratégicos (de crear fuertes y avanzadas defensivas) bajo apariencias humanitarias. ${ }^{59}$ Además de los ricos elementos que avalan estas sugerentes hipótesis, podríamos aportar alguna otra evidencia empírica más, en la dirección de apoyar las explicaciones brindadas por los tres primeros estudiosos mencionados. En efecto, esa tendencia de los gallegos a

55 Para un interesante análisis de las contratas, véase Porro Gutiérrez, Jesús María: La emigración asturiana ..., págs. 26-28.

56 Ibídem, págs. 83 y 84. Según Jesús María Porro Gutiérrez, se trasladaron unos 2.050 sujetos en estas campañas pobladoras. Juan Alejandro Apolant ha calculado que el número total de personas desembarcadas en Montevideo habría sido de 1.921. Apolant, Juan Alejandro: Operativo Patagonia ..., pág. 153.

57 Eiras Roel, Antonio y Rey Castelao, Ofelia: Los gallegos ..., pág. 180; Porro Gutiérrez, Jesús María: La emigración asturiana ..., págs. 31 y 32.

58 Artaza Montero, Manuel María de: "Los ilustrados gallegos ...”, pág. 201.

59 Saurín de la Iglesia, María Rosa: "La emigración a Indias ...”, pág. 311. 
migrar solos, alimentada por las antiguas tradiciones de desplazamientos espaciales intrapeninsulares, también parece haberse puesto de manifiesto en lo relativo a las campañas en consideración, pese a que con estas últimas, como ya aclaramos, se proponía fomentar el traslado ultramarino de familias completas. Si examinamos cómo se conformaron los núcleos pobladores que partieron de La Coruña, en las sucesivas expediciones (ver el Cuadro 1, en el Anexo), podremos comprobar que los gallegos tendieron a migrar sin familiares o conocidos en mayor medida que los asturianos, por ejemplo. ${ }^{60}$ Un $13 \%$ de los núcleos emigratorios gallegos estuvieron conformados por un jefe solo, mientras que entre los asturianos, ese porcentaje fue tan sólo del 1\%. Los oriundos del Principado se ajustaron en mayor medida a los requerimientos de la monarquía de transportar familias enteras. Estimulados por la propaganda oficial, pero también, debido a la acción de otros mecanismos más espontáneos (el poder de convencimiento de algunos pobladores sobre otros parientes o paisanos), los jefes asturianos lograron movilizar redes sociales más amplias que sus pares gallegos. Quizás esta última circunstancia contribuya a explicar el hecho de que el número total de migrantes asturianos sumados a las expediciones fue mayor que el de los gallegos. Resulta interesante agregar que esas vinculaciones personales podían rebasar al núcleo migratorio propiamente dicho, y ligar a varios de ellos, tal como se desprende del ejemplo que brindamos en el Gráfico 1, en el Anexo. En el mismo nos propusimos dejar plasmadas las relaciones que existieron entre seis núcleos emigratorios asturianos. Se trataba de lazos familiares, que en algunos casos, se superponían a los paisanales (tengamos en cuenta que la mayoría de los sujetos que se encuentran incluídos en el Gráfico 1 pertenecían al concejo de Villaviciosa, y dentro de este último, a cuatro parroquias aledañas, en el noroeste del mismo: Quintueles, Quintes, Castiello y Arroes).

Ahora bien, más allá de la necesidad de ampliar el área inicial de colectación hasta Asturias o Castilla-León, no tardaron en surgir otros contratiempos logístico-organizativos ligados a las expediciones en cuestión, tanto dentro del destino transitorio de los colonos (Montevideo), como den-

60 El análisis, que comprendió todos los núcleos emigratorios enlistados en La Coruña, fue llevado a cabo a partir de la siguiente documentación y bibliografía: AMC, Cajas Río de la Plata, 1780, 1783-1792, Libro de Filiaciones de las Familias del Principado de Asturias que principia en $1 .^{\circ}$ de octubre de 1779; Libro de Filiaciones del Reyno de Galizia (sic), de las Personas que se alistan para pasar a las Provincias del Río de la Plata desde primero de octubre de 1778, sin catalogar; Apolant, Juan Alejandro: Operativo Patagonia ..., págs. 227-387. 
tro de los concebidos como finales (los asentamientos de la costa patagónica). En la primera ciudad mencionada, y según un informe del Intendente de Buenos Aires, Manuel Ignacio Fernández, los gallegos intentaron fugarse, para "evadirse de seguir al destino con que vienen". ${ }^{61}$ Así explicaba la situación el funcionario en cuestión:

Como esta gente es pusilánime por naturaleza, y fueron informados desde que llegaron a Montevideo que no debían poblar en las orillas del Río de la Plata, bajo cuya condición aseguran que hicieron su contrata con el Intendente del Exército de Galicia, sino en los nuevos establecimientos de la Costa de Patagones, han empezado a disgustarse inducidos o animados de tantos desertores de marina, y polizones como existen en Montevideo, que los más son de su propio País, y también les ha infundido el mayor terror el naufragio de la Urca Visitación, en donde se hallaban embarcados los más de ellos para su conducción al Puerto de San Josef, pues costó bastante trabajo sujetarlos a que se embarcasen los que se hallan en el establecimiento del Río Negro, como no menos a los que salieron para la Bahía de San Julián. ${ }^{62}$

Como podemos apreciar a partir de este pasaje citado, el traslado desde Montevideo a la costa patagónica no estuvo exento de tensiones y resistencias, por parte de los nuevos pobladores. La revelación de su verdadero destino, la insuficiente asignación para su manutención diaria y otros incidentes fortuitos (como el naufragio de una de las naves que debía conducirlos a la porción austral del Continente), fueron algunos de los factores que los afectaron negativamente en la primera etapa de su periplo. Posteriormente aparecieron nuevos problemas. Una vez que los colonos fueron trasladados a la costa patagónica, las duras condiciones naturales de la región impidieron el desarrollo de una vida normal. Los peninsulares establecidos en la Bahía de San Julián y en el Fuerte del Carmen, al año y medio de haber llegado, dejaron sentir sus protestas por el tipo de existencia a la que estaban sometidos. A las enfermedades que afectaban a jóvenes y ancianos por igual, se sumaba la falta de alimentos, la imposibilidad de obtener cultivos, la rigurosidad del clima, la carencia de leña y de vestidos. En pocas palabras, los pobladores sentían que habían sido "engañados", y que se los trataba "peor que a los presidiarios". ${ }^{63}$ En el estableci-

61 AGI, Audiencia de Buenos Aires, 326, Expedientes sobre familias pobladoras e incidencias en la Costa Patagónica, 1778-1780, fol. 1.

62 Ibídem, fol. 2.

63 Apolant, Juan Alejandro: Operativo Patagonia ..., págs. 124-127; Vilanova Rodríguez, Alberto: Los gallegos ..., Vol. I, pág. 194. 
miento del Río Negro no había habitaciones suficientes para acomodar a los migrantes, que eran empleados en la construcción de un fuerte de piedra, que se esperaba pudiera resistir los ataques de los "indios bárbaros". Tanto las personas trasladadas como las autoridades metropolitanas e indianas eran conscientes del enorme gasto improductivo que esta empresa estaba suponiendo para la Real Hacienda. ${ }^{64}$ Se imponía tomar alguna medida, al menos para contener los reclamos de los recién llegados, que se hallaban sumidos en la pobreza. En estas circunstancias se comenzó a barajar la posibilidad de reubicarlos en pueblos o fortalezas amenazados por la presencia portuguesa o por los "indios infieles". Con este tipo de iniciativa también se buscaba fomentar la agricultura en otros parajes, limitar el contrabando y garantizar la actividad comercial, que peligraba por la inseguridad de algunas rutas. ${ }^{65}$ Paralelamente, se suspendió el envío de nuevos colonos a la costa patagónica, hasta tanto se pudieran reacomodar los que aún permanecían en Montevideo. ${ }^{66}$

Las familias fueron redistribuídas entonces en diferentes pueblos o ciudades de la Banda Oriental (Montevideo, Maldonado, Colonia, Rosario, San José, Santa Lucía, Canelones, Pando, Minas o San Carlos, principalmente), y en distintas Guardias de Buenos Aires (Rojas, Salto, Luján, Monte, Ranchos o Chascomús). ${ }^{67}$ Sin embargo, en estos nuevos destinos volvieron a surgir inconvenientes: a las privaciones de todo tipo experimentadas por la mayoría de los colonos, se sumó la suspensión del pago del real diario, que la corona se había comprometido a sufragar a cada poblador, hasta tanto se les asignara una morada fija. Los colonos reaccionaron de manera mancomunada, reclamando el auxilio monetario que se les debía, logrando que la monarquía les reconociera finalmente este derecho, en la mayoría de los casos. ${ }^{68}$

64 AGI, Audiencia de Buenos Aires, 328, Expedientes sobre familias pobladoras e incidencias en la Costa Patagónica, 1783-1791, fol. 1; AGN, BN, Patagonia. Documentos del Archivo de Indias, "Carta del Intendente de Buenos Aires al Ministro Gálvez", 30 de mayo de 1780, 196, fols. 234-235.

65 Ibídem, fols. 238-239; AGI, Audiencia de Buenos Aires, 327, Expedientes sobre familias pobladoras e incidencias en la Costa Patagónica, 1781-1783, fols. 2 y 3.

66 AGN, BN, Patagonia. Documentos del Archivo de Indias, "Correspondencia del Virrey Vértiz sobre la suspensión de remitir los colonos a los nuevos establecimientos de la Costa Patagónica", 20 de junio de 1780, 196, fols. 335 y 336.

67 En su apéndice documental, Juan Alejandro Apolant incorporó la lista de pobladores que halló en el Archivo General de la Nación, de Montevideo. Allí figura el destino final asignado por la Corona a los colonos, lo que permite tener una clara idea de la magnitud de la dispersión de estos últimos, dentro del área rioplatense. Véase Apolant, Juan Alejandro: Operativo Patagonia ..., págs. 223-387. 68 AGN, Colonial, Interior, IX 30-7-1, 3; y IX 30-3-4, 14. 
No obstante, no hubo ninguna medida encaminada a establecer de forma definitiva a los pobladores llegados de España. Hacia 1791 aún quedaban 642 de ellos "sin destino fijo" en Maldonado y San Carlos, y 335 en Montevideo. ${ }^{69}$ Otros se habían dispersado por el interior virreinal, e incluso, sabemos que algunos terminaron instalándose en la capital. Aquellos que habían sido colocados en las Guardias de Buenos Aires a menudo vieron amenazado su derecho a la posesión de la tierra - fijado en las contratas suscritas en España- por poderosos hacendados que reclamaban la propiedad de los territorios donde estaban asentados. Estas situaciones crearon conflictos judiciales que llegaron a los Tribunales del Superior Gobierno. ${ }^{70}$

Hacia 1796, en la Guardia de Chascomús y otras bonaerenses, los pobladores se habían visto obligados a abandonar sus terrenos de labranza, en virtud de que algunos "hombres ricos" habían logrado reivindicarlos exitosamente, como parte de su propiedad. ${ }^{71}$ El conflicto que tuvo lugar en la Guardia de Ranchos, que finalmente supuso una resolución satisfactoria para los colonos, ilustra el tipo de tensiones suscitadas en torno a la tierra. Todo comenzó cuando Don Manuel Izquierdo, vecino de Buenos Aires, estanquero y hacendado de Ranchos, reclamó el título de propiedad de los terrenos donde estaban instaladas varias familias pobladoras, con su descendencia. Estas últimas se organizaron para promover un expediente judicial, donde exigieron que se respetara su derecho a la posesión de la tierra. Fundaban además su pedido en el reconocimiento que ameritaban los fieles servicios que habían prestado al Monarca, desde su llegada a Ranchos en el año 1781: no sólo habían cultivado el suelo que se les había asignado, sino que también lo habían defendido de los "indios infieles", dando el producto debido al Rey y a la Iglesia. Y todo ello lo habían logrado pese a que cuando arribaron a la Guardia en cuestión no tenían más que una yunta de bueyes y una "cuartilla de maíz y media de porotos". ${ }^{2}$ Manuel

69 AGN, Colonial, Interior, IX 30-3-4, 14, fols. 60-62.

70 Archivo Histórico de la Provincia de Buenos Aires (en adelante, AHPBA), Escribanía Mayor de Gobierno, Chascomús, Pobladores de Chascomús, R.1-L.12-E 422/0, 1787; AHPBA, Escribanía Mayor de Gobierno, Ranchos, Pobladores de Ranchos, R.1-L.4-E 110/0, 1797; AHPBA, Escribanía Mayor de Gobierno, Guardia de Luján, Vecinos de Guardia de Luján, R.1-L.14-E 483/0, 1798. Una querella similar por la tierra, en la que participaron pobladores que no habían venido en las expediciones analizadas, puede consultarse en AHPBA, Escribanía Mayor de Gobierno, Luján, Pobladores de la Frontera, R.1-L.11-388/0, 1786.

71 AHPBA, Escribanía Mayor de Gobierno, Ranchos, Pobladores de Ranchos, R.1-L.4-E 110/0, 1797, fols. 3 y 4.

72 Ibídem, fols. 1 y 3. 
Izquierdo había introducido una gran cantidad de ganado en los terrenos donde estaban establecidos, quitándoles pastos y bebidas para sus animales. Además, era factible que una vez que adquiriera su título de propietario, les exigiera el pago de arrendamientos. La acción conjunta de los pobladores, representados por el asturiano Adriano de la Infiesta, logró de modo algo llamativo un resultado favorable: el Tribunal decidió anular la venta verificada al enriquecido hacendado, por la "malicia con que se ha conducido en ella", devolviéndole el dinero pagado, y dejando a los pobladores en las tierras que ocupaban. ${ }^{73}$

A un nivel más individual, podemos comprobar que los periplos de los migrantes peninsulares en cuestión fueron en general muy penosos, no sólo por los sinsabores del propio traslado (en el que solían demorarse más de tres meses, en malas condiciones higiénicas y con una muy escasa alimentación), sino también, por los sucesivos desplazamientos a los que fueron sometidos en el espacio rioplatense, sin que se les garantizaran los medios de subsistencia básicos. Contamos, por ejemplo, con la declaración de Cipriano Antonio Gómez, quien recordaba haber llegado en el año 1779 como poblador a Montevideo, en la Fragata "N. S. del Socorro". Lo acompañaban en esta empresa unas 83 personas. De la mencionada ciudad fue conducido a las costas patagónicas con otros 19 individuos solteros. Allí, una peste de escorbuto azotó al contingente, ya bastante debilitado como consecuencia de una dieta pobre. Una orden superior los instó a abandonar el lugar. Los pobladores enfermos fueron conducidos en el Bergantín Carmen a Buenos Aires. ${ }^{74}$ En su nuevo destino, la suerte de Cipriano Gómez no fue mejor:

[...] viéndome abandonado en igual que otros compañeros sin suministrar los auxilios que ofreció el Rey, sin señalarnos tierras con lo necesario para su cultivo, y en un estado cuasi de mendigo, tuve por conveniente a fin de proporcionarme los medios de subsistir, de pasar a la ciudad de Córdoba con la licencia que me otorgó para ello el Exmo. Sr. Don Juan Josef de Vértiz entretanto se determinaba por este Superior Gobierno el acomodamiento y colocación de remate de los pobladores para la que no he sido hasta ahora citado, ni prevenido, sin embargo de haber tenido apoderado nombrado en esta Capital para que promoviese este negocio $[\ldots] .^{75}$

73 Ibídem, fols. 16 y 17.

74 AGN, Colonial, Interior, IX 30-7-6, 2653, 8, fols. 3 y 4.

75 Ibídem, fol. 7. 
Este poblador, obligado a trasladarse a Córdoba del Tucumán para garantizar su supervivencia, había solicitado ya dos veces que se le abonara el real diario que la corona le debía, incluyendo a toda su familia en este reclamo. La Junta Superior de la Real Hacienda resolvió satisfacer parcialmente esta demanda, estipulando que entregaría el real diario que correspondía a Cipriano únicamente (y no a sus hijos). En cambio, le ofreció un terreno realengo en las inmediaciones de la ciudad de Córdoba, donde podría instalarse con su esposa y descendencia.

El asturiano Luis de Génova y su familia también vieron en gran medida frustradas sus expectativas. Trasladados por disposición del Marqués de Loreto a la población del Real de San Carlos, el mencionado colono terminó recibiendo una chacra a tres o cuatro leguas de la misma. En dicho terreno pudo construir "un pequeño y agujereado rancho de paja con una cocinita de lo mismo". Hacia 1798 no tenía animales en su corral. Tampoco poseía sementeras de lino, sino un poco de trigo, con un "huertecito sembrado con un puñado de semilla de cáñamo", que "aunque lo llegase a cosechar no podría servir de otra cosa su fruto que dar una señal cierta de que lo producía la tierra" ${ }^{76}$ Para "remedar las necesidades de su familia" había cortado algo de leña en el Arroyo del Sauce, lo que lo involucró en un litigio con Alexandro Reyes, quien sostenía que esas tierras le pertenecían y que por lo tanto, no podían ser aprovechadas por el poblador. ${ }^{77}$ Como vemos, la supervivencia se tornaba difícil en los casos en que los colonos, colocados en destinos desconocidos y alejados de ámbitos urbanos, quedaban desprovistos de la asistencia de lazos comunitarios o paisanales, o no lograban una inserción laboral favorable.

Sin embargo, también fue posible que algunos emigrantes llegados en las expediciones organizadas por la corona transitaran algunos caminos de movilidad social ascendente. En el caso de las mujeres, un matrimonio conveniente podía garantizar un buen nivel de vida, a mediano o incluso, a largo plazo. Los hombres, entre otras vías, podían verse favorecidos si contaban con algún capital que les permitiera iniciar inversiones en el comercio o en la producción. Detengámonos brevemente en dos casos que pueden quizás ejemplificar estas últimas afirmaciones.

La asturiana Joaquina Migoya fue trasladada en la misma fragata que Luis de Génova (la denominada "San Josef"), pero su suerte fue bastante

76 AGN, Colonial, Tribunales, IX 34-9-4, 1, 7, fols. 16 y 17.

77 Ibídem, fols. 3-10. 
distinta a la de este último colono. ${ }^{78}$ Había salido de La Coruña el 15 de abril de 1781 y arribó al puerto de Montevideo el 19 de julio del mismo año. La acompañaron en el mismo viaje sus padres y sus cinco hermanos, además de unos 561 pobladores más. Pasaron primero a la capital virreinal (el 19 de septiembre de 1781) y luego fueron destinados a la Guardia de Ranchos (a donde se desplazaron el 1 de octubre de 1781). El 22 de marzo de 1792 Joaquina se casó en la Catedral de Buenos Aires con Miguel de Caldevilla, un comerciante asturiano bastante importante para la época, con vínculos mercantiles en amplias zonas del interior virreinal. Cuando contrajo nupcias, la joven no ingresó a su sociedad conyugal más que la "decencia de su persona". Sin embargo, a la muerte de su esposo, recibió como parte de su herencia unos 11.800 pesos en dinero, muebles y alhajas, pudiendo introducir también a su segundo matrimonio una casa, que Caldevilla le cedió para que disfrutara "durante sus días", con la obligación de que luego quedara a beneficio del Hospital de Mujeres de la ciudad. Su primer marido también benefició a un hermano de Joaquina, Juan, habilitándolo en una tienda en Luján y dejándole en herencia una casa contigua en la misma villa. Si bien gracias a su primer matrimonio, Joaquina pudo mejorar su posición, el segundo enlace con Félix García no la benefició en igual medida: este consorte terminó arrestado varias veces por embriaguez y dilapidó no sólo el capital que introdujo a la sociedad conyugal, sino también parte de la dote de su esposa y los gananciales. Joaquina también se vio obligada a entregar "unos restos de almacén que poseía" a su hijo Juan Antonio, por "el abandono en el que había caído su marido". Como podemos apreciar a través de esta historia, el matrimonio también podía precipitar a la mujer en la desgracia, aunque estos casos en general han dejado menos huellas en la documentación disponible.

Pedro Pidal, natural de la Jurisdicción de Villaviciosa, en el Principado de Asturias, también llegó en la fragata "San Josef", el 19 de julio de 1781. De estado soltero, venía acompañado por su madre, María Rivero, su hermano, Juan Pidal, y su cuñada, María Josefa Arce. ${ }^{79}$ Como Joaquina

78 La información para reconstruir sucintamente esta historia de vida fue tomada de: AGN, Sucesiones, 6782, Joaquina Migoya; AGN, Sucesiones, 5345, Miguel de Caldevilla; AGN, Gobierno Colonial, Padrones Generales de los habitantes de Buenos Aires de 1806 y 1807, IX 9-7-7; y Censo de Buenos Aires de 1810, S IX 10-7-1; Jáuregui Rueda, Carlos: Matrimonios de la Catedral de Buenos Aires. 1747-1823, Fuentes Históricas y Genealógicas Argentinas, Buenos Aires, 1989, pág. 247; Apolant, Juan Alejandro: Operativo Patagonia..., pág. 344.

79 Para la trayectoria del poblador Pedro Vidal hemos consultado AGN, Sucesiones, 7387, Pedro Pidal; y Apolant, Juan Alejandro: Operativo Patagonia..., págs. 335 y 356. 
Migoya, pasó primero a Buenos Aires y luego a la Guardia de Ranchos. Allí contrajo matrimonio con María Fernández, quien era hija de otros dos pobladores: Francisco Fernández y Josefa Soare. Esta última pareja se había embarcado en La Coruña en la misma fragata que Pedro Pidal, junto a sus cinco hijos y la hermana de Francisco, Josefa Fernández. Al momento de su enlace con María Fernández, Pedro Pidal introdujo a su matrimonio 1.015 ps. 4 rs., mientras que a lo largo del mismo, obtuvo como gananciales 4.606 ps. 2 y $3 / 4$ rs. Evidentemente, durante los años que duró su sociedad conyugal, este asturiano logró acrecentar su capital (sin llegar a detentar una gran fortuna para la época). Probablemente, esto último fue posible gracias a que contaba con cierto dinero antes de contraer nupcias con María, lo que le debe haber permitido iniciar sus actividades comerciales y productivas en el ámbito rioplatense. Tengamos presente que al momento de su muerte, Pedro poseía dos pulperías, a cargo de su cuñado Francisco Fernández y de su entenado Simón Cabezas, al tiempo que era dueño de una gran tahona, con un importante número de mulas y caballos. Entre sus bienes se contaban, además, dos ranchos, trigo y cueros, muebles, dos casas en la ciudad de Buenos Aires, dos mil pesos en efectivo y una criada.

Más allá de estas trayectorias personales, que revelan ciertamente algunos ángulos de este proyecto borbónico, el balance de la empresa en su conjunto probablemente sea más negativo que positivo. La monarquía no logró cumplir sus objetivos de crear "avanzadas de población" permanentes en las costas patagónicas. Lejos de ello, sometió a los colonos a un sinfín de incertidumbres y penurias. Sus destinos finales fueron en muchos casos azarosos, en lugar de corresponder a los señalados por las autoridades. Posiblemente la corona no conocía suficientemente las condiciones naturales y culturales de la porción meridional del Continente Americano, y como consecuencia de ello, se propuso metas poco viables. Las protestas de los colonos por las promesas incumplidas y por las malas condiciones de vida a las que quedaron expuestos, ponen también de manifiesto que el Estado español no se comprometió todo lo necesario en esta empresa, fundamentalmente, a un nivel financiero.

Sin embargo, es interesante señalar que la política de fomento de la emigración, defendida por el gobierno metropolitano, no se limitó únicamente a las campañas pobladoras que acabamos de analizar. También involucró al ejército, que de algún modo, quedó convertido en otra vía de poblamiento. Según la normativa en vigor, los militares peninsulares que cumplían su servicio en América, debían regresar a España una vez que el 
mismo finalizaba (como mínimo, a los ocho años), o en caso de quedar inválidos. Sin embargo, sucesivas disposiciones oficiales fueron autorizando a los soldados que se hallaban en determinadas condiciones, a permanecer en suelo americano. En primer lugar, esto último fue posible para aquellos que al término de su servicio se encontraban casados. Como estipuló la Real Orden del 20 de agosto de 1786:

[...] los soldados europeos, que sean casados en América, y cumplan el tiempo de su empeño, pueden, si quieren, permanecer en estos dominios en calidad de Pobladores donde el Gobierno los destine; y en los casos que ocurran se tomarán los acuerdos que son consiguientes a esta Real determinación, y las posibles precauciones para evitar licencias de abusivos casamientos, que puedan intentarse, especialmente al tiempo de deberse restituir a España los individuos, como se sirve V. E. prevenirme $\left[\ldots . .{ }^{80}\right.$

Posteriormente, esta disposición se extendió a los Sargentos y Cabos, con lo cual quedó demostrado el interés del gobierno por aumentar el número de pobladores estables en territorios de ultramar. ${ }^{81} \mathrm{Tal}$ como se desprende de documentación de la época, ambas Reales Órdenes no tardaron en ser instrumentalizadas por aquellos militares que terminaron contrayendo nupcias en suelo americano, con el fin de establecerse definitivamente en el mismo (tendencia que incluso la citada Real Orden buscaba limitar). ${ }^{82}$

En segundo lugar, los sargentos y cabos que aún no habían concluido su servicio, pero que por su "inutilidad u otro motivo justo" preferían separarse del mismo, también fueron autorizados a afincarse en el espacio del Virreinato del Río de la Plata y a ejercer allí las artes u oficios que prefirieran. ${ }^{83}$ En tercer lugar, un integrante de la tropa podía manifestar su interés por "tomar el estado religioso". En estas condiciones, y siempre y cuando demostrara una auténtica vocación, se le podía conceder el permiso de adoptar los hábitos, y por lo tanto, se lo exceptuaba de retornar a la Península ${ }^{84}$ Por último, en 1795 se estipuló que los soldados cumplidos que

80 AGN, Colonial, Subinspección 1787-1788, IX 28-6-4, sin folio. Ya desde 1778 José Cornide bregaba por la transformación de los militares españoles en colonos. Esta última medida buscaba emular la adoptada por el Parlamento inglés, el cual había promovido el establecimiento de soldados en Acadia, Nueva Escocia o Halifax, para aumentar su población, una vez terminada la guerra de 1748. Véase Cornide, José: “Observaciones sobre el establecimiento...”, págs. 25-26.

81 AGN, Colonial, Subinspección 1787-1788, IX 28-6-4.

82 Los casos comentados pueden revisarse en Ibídem.

83 Archivo General de Simancas (en adelante, AGS), Secretaría, Guerra, 6801, 52, Repoblación. Licencias absolutas, 1787-1788, fol. 341.

84 AGN, Colonial, Subinspección 1787-1788, IX 28-6-4, "Carta de Antonio Olaguer Feliu, del 12 de julio de 1788 ", sin folio. 
se hallaban en las Provincias del interior del Virreinato, podían permanecer en ellas, para evitar costos de transporte a España, deserciones, y con el fin de que se convirtieran en una fuerza potencialmente movilizable, en caso de necesidad. ${ }^{85}$ La disposición en la materia prescribía que a los militares en cuestión:

[S]e les concedan sus licencias con entera libertad de subsistir en aquellos Dominios, casándose, domiciliándose o estableciéndose con algún arbitrio, destino, oficio u ocupación honrada para mantenerse con fidelidad y conducta, bajo la obligación de presentarse a los respectivos Comandantes de Armas en cualquiera conmoción, alboroto o urgencia, y con las precauciones o seguridades consiguientes que en sus debidos casos se estimen justas. ${ }^{86}$

En pocas palabras, a los soldados destacados en América se les fueron abriendo oportunidades para instalarse allende el océano. La posibilidad de integrarse a la sociedad colonial a través del matrimonio, o a partir de la obtención de un empleo conveniente, alentaron en algunos casos su predisposición a permanecer en tierras ultramarinas. Las disposiciones comentadas vinieron a legitimar una situación que de hecho ya se venía produciendo, a la luz del creciente número de desertores que intentaban forjarse un porvenir en el Nuevo Mundo, al margen de la ley. ${ }^{87}$ En este sentido, el interés de la corona española de convertir al ejército en un medio indirecto de poblamiento coincidió con el propósito de muchos soldados de permanecer en tierras americanas.

Tenemos evidencias de que algunos gallegos y asturianos aprovecharon las vías legales que ofrecía el ejército, para quedarse en el Virreinato del Río de la Plata. En agosto de 1787 Juan Joseph Díaz, retirado del cuerpo de Blandengues, presentó su petición para casarse con Antonia Meneses, de "familia española conocida", con lo cual, al poco tiempo, obtuvo el permiso para afincarse en tierras de ultramar. Por otra parte, el Sargento Segundo de Granaderos del Cuerpo de Saboya, Blas Castro, natural de Lugo, fue separado del servicio con licencia absoluta, y autorizado a quedarse en la capital virreinal, "por conceptuarse sin cura el afecto que tiene al pecho, y la sangre

85 AGS, Secretaría, Guerra, 6810, 13, Soldados pobladores, 1790-1793, fols. 67-69; y 40, Soldados pobladores, 1790-1795, fols. 154-157.

86 Ibídem, fols. 156 y 157.

87 AGN, Colonial, Subinspecciones 1787-1788, 1788-1789, 1793-1796, "Relaciones de la fuerza con que se hallan los Cuerpos Veteranos que guarnecen esta Provincia, número que falta para su completo, con noticia de la alta y baja ocurrida en el mes próximo pasado", IX 28-6-4; IX 28-6-5; IX 28-6-7, sin folio. 
que echa por la boca". Otro Granadero del mismo cuerpo, Joseph Pita, de origen gallego, también fue exceptuado de regresar a la Península, "por padecer afecto al pecho y dolores artríticos en todos sus extremos" ${ }^{88}$ Es difícil saber si en casos como los dos últimos, los soldados padecían realmente de las enfermedades declaradas, o si tenían la deliberada intención de mostrarse convalecientes e imposibilitados de emprender el viaje ultramarino (por ejemplo, si contaban con la complicidad del cirujano y de los coroneles de los cuerpos, para la presentación de un diagnóstico médico que los respaldara en su propósito). Esto último debió ocurrir con cierta frecuencia, a juzgar por el descargo del Inspector de las tropas del Virreinato del Río de la Plata, Antonio Olaguer Feliu, ante su superioridad, en el que afirmaba que había que tomar las precauciones necesarias en relación con los soldados enfermos "a fin de cuidar también por parte de V. E. que no queden fraudulentamente en estos dominios, como previene S. M., correspondiendo sólo por la mía el vigilar, como lo he hecho, y haré en los sucesivo, que no se separen del servicio para quedar en estas Provincias, sino es aquellos que padezcan achaques moralmente imposibles de curar, y que al mismo tiempo les imposibiliten embarcarse". ${ }^{89}$

En cuanto a la adopción del estado religioso, a lo largo de los últimos años de la etapa colonial hubo muchos militares que se inclinaron por tomar los hábitos, en especial, dentro de la Orden de San Francisco. Como lo reconocía el mismo Antonio Olaguer Feliu, esta última decisión respondía en algunos casos al deseo de los soldados de querer separarse del ejército. ${ }^{90}$ Para comentar un ejemplo, Francisco de Castro y Pardo, Cabo Segundo de Granaderos del Regimiento de Infantería, expuso en dos ocasiones y ante las autoridades su interés por ingresar a la Orden franciscana. Tras la primera petición, no obtuvo una respuesta positiva. Sin embargo, luego de la segunda solicitud, pudo alcanzar sus objetivos: no sólo logró permanecer en el Río de la Plata, entrando a la mencionada Orden, sino que también pudo retirarse de su servicio, antes de cumplir con el período exigido. ${ }^{91}$

88 Todas las situaciones comentadas pueden revisarse en AGN, Colonial, Subinspección 17871788, IX 28-6-4.

89 Ibídem.

90 Ibídem. Otros casos vinculados a la cuestión señalada, en AGN, Colonial, Subinspección 1788-1789, IX 28-6-5; y Subinspección 1793-1796, IX 28-6-7.

91 AGN, Colonial, Subinspección 1787-1788, S IX 28-6-4. 


\section{Las ambigüiedades de las políticas migratorias}

A fines de la etapa moderna las salidas de gallegos y asturianos al exterior (tanto a diferentes ámbitos peninsulares como ultramarinos) despertaron el interés de algunos pensadores ligados a la monarquía borbónica y de la propia corona. Las contrapuestas visiones que se forjaron sobre dichos desplazamientos humanos alimentaron una ambigua política migratoria. En consonancia con la percepción negativa de las migraciones, en tanto movimientos que producían la despoblación del suelo español, y el consecuente debilitamiento del cuerpo social, se defendió el imperativo de restringir y seleccionar los flujos migratorios. Ello encontró una legitimidad legal en la sanción del "Reglamento para el Comercio Libre", a fines del siglo XVIII.

Pero por otro lado, y en relación con aquella otra concepción más positiva de los movimientos espaciales de peninsulares, se sostuvo la necesidad de fomentar campañas de poblamiento en el Nuevo Mundo. Estas últimas estuvieron encaminadas a garantizar el control sobre territorios amenazados por la presencia de potencias extranjeras o por la existencia de fuerzas locales capaces de cuestionar el dominio colonial. En general, y tal como queda de manifiesto en el caso de las expediciones al Río de la Plata analizadas, dichas empresas tuvieron un éxito limitado. El objetivo de consolidar el poder hispánico en espacios alejados de la férula estatal se vio en gran medida frustrado: los colonos no pudieron resistir las duras condiciones de vida locales, y la corona no dispuso de los recursos suficientes para sostener el emprendimiento planificado. Los peninsulares tuvieron que ser reconducidos a destinos diferentes a los inicialmente asignados por el gobierno español, integrándose de modos diversos y con variable éxito a la sociedad de acogida. Sin embargo, y más allá de estos resultados poco alentadores, la mera planificación y ejecución de las campañas en cuestión, junto con las disposiciones oficiales que autorizaron a los soldados a permanecer en América, permiten corroborar que aquella idea de restringir las salidas de españoles al exterior, presente desde los primeros tiempos de la conquista y colonización, coexistió a fines de la etapa moderna con otra aparentemente opuesta y contradictoria: la de alentar dichos desplazamientos humanos, con fines estratégicos.

Recibido el 20 de abril de 2006 Aceptado el 25 de julio de 2006 



\section{Anexo}

\section{CUADRO 1}

MODALIDADES DE TRASLADO DE LOS JEFES POBLADORES DEL NOROESTE HISPÁNICO AL RÍO DE LA PLATA (1778-1784)

\begin{tabular}{lcccc} 
& \multicolumn{2}{c}{ Gallegos } & \multicolumn{2}{c}{ Asturianos } \\
\cline { 2 - 5 } Modalidades de traslado & $N^{*}{ }^{\boldsymbol{o}}$ & $\%$ & $N^{\boldsymbol{o}}$ & \multicolumn{1}{c}{$\%$} \\
\hline Jefes solos & 11 & $\mathbf{1 3 \%}$ & 1 & $\mathbf{1 \%}$ \\
Jefes con familiares o conocidos* & 72 & $87 \%$ & 98 & $99 \%$ \\
\hline Total & 83 & $100 \%$ & 99 & $100 \%$
\end{tabular}

* Los familiares podían formar parte del grupo emigratorio principal o de la/s compañía/s. Los conocidos integraban únicamente estas últimas. Las compañías estaban constituídas por un conjunto de personas que se alistaba al lado del grupo principal y que quedaba subordinado al jefe del mismo.

Fuentes: Elaboración propia, a partir de AMC, Cajas Río de la Plata, 1780, 1783-1792, Libro de Filiaciones de las Familias del Principado de Asturias que principia en 1. ${ }^{\circ}$ de octubre de 1779; Libro de Filiaciones del Reyno de Galizia, de las Personas que se alistan para pasar a las Provincias del Río de la Plata desde primero de octubre de 1778, sin catalogar; Juan Alejandro Apolant, Operativo Patagonia. Historia de la mayor aportación demográfica masiva a la Banda Oriental, Montevideo, 1970, págs. 227-387. 
NADIA ANDREA DE CRISTÓFORIS

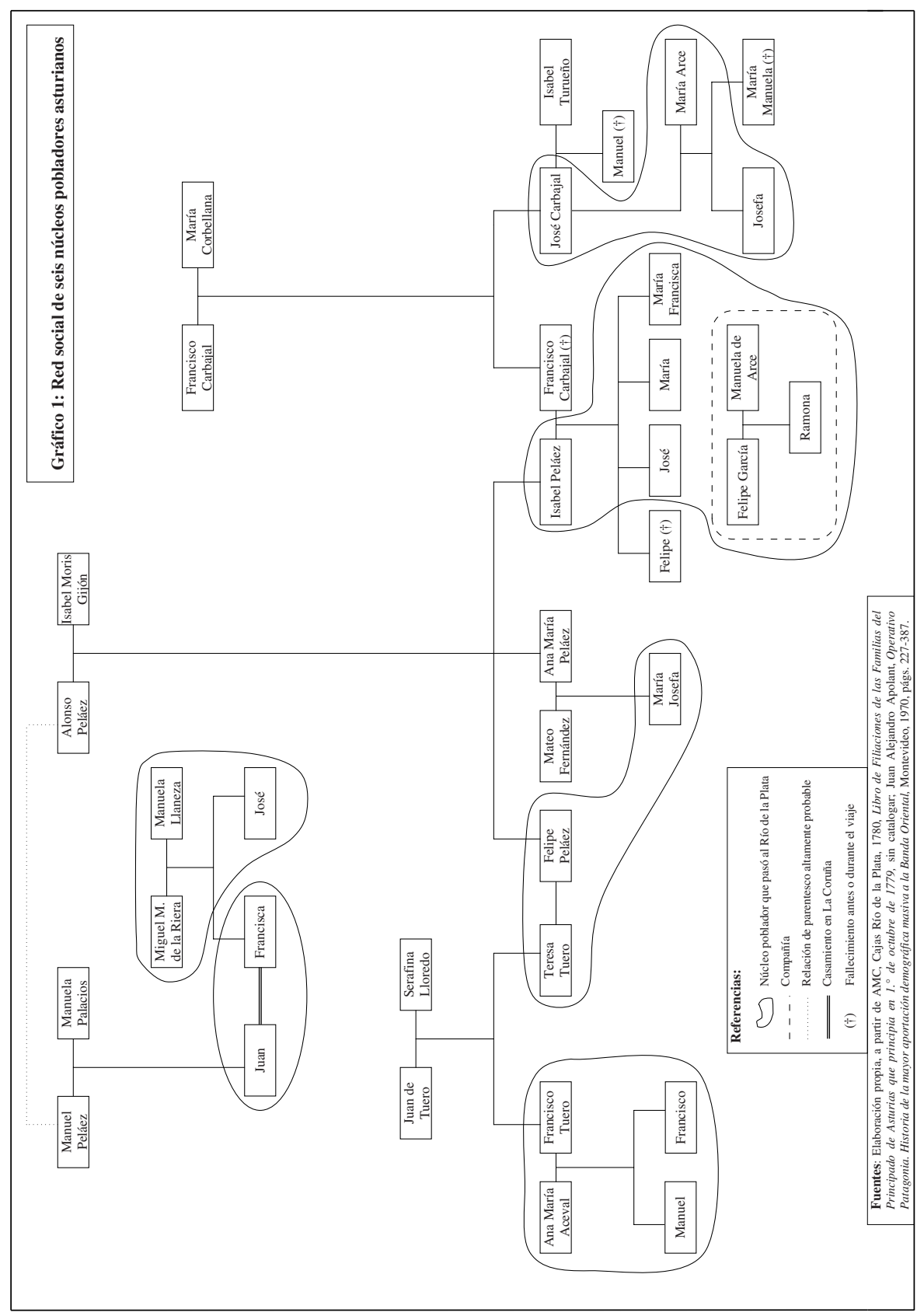

150

AEA, 63, 2, julio-diciembre, 2006, 117-150. ISSN: 0210-5810 